\title{
VINCULACIÓN HISTÓRICA ENTRE CASTILLA Y AMÉRICA A LO LARGO DE CINCO SIGLOS
}

\author{
María Teresa Ruiz de la Parte. \\ Federación de Centros Castellanos. Madrid. España.
}

La vinculación entre Castilla y América cuenta con el más importante de los vínculos, el castellano. La lengua, la religión y la cultura, que la corona de Castilla llevó a las Américas recién descubiertas, crea entre ambas tierras unos lazos indiscutibles e indestructibles.

Las tres carabelas, que el doce de Octubre de 1492 arribaron a las costas del continente americano, llevaban la bandera que en la actualidad es la de la comunidad Castellano-Leonesa, los castillos y leones rampantes.

Pero es antes de esta fecha, cuando Castilla y América, comienzan esa larga y fructífera relación que durará hasta nuestros días. Ya que en 1486, Fray Diego de Deza, natural de Toro y por aquel entonces obispo de Palencia, entra en contacto con Cristóbal Colón, que venía de presentar su proyecto en Portugal, donde había sido rechazado.

Fray Diego de Deza, consejero de la Reina Católica, se convierte en el defensor a ultranza del a primera vista, quimérico proyecto de Colón. El será quién intervenga para dar a conocer a Isabel I de Castilla dicho proyecto. La Reina se interesa en un principio en el mismo, pero cautelosa, encarga que estudien el proyecto de Colón a la Junta de Salamanca, que estaba integrada por catedráticos de esa Universidad, y a la cual también pertenecía Fray Diego de Deza.

La Junta de Salamanca se reúne en 1486 en la iglesia de San Esteban, y después de escuchar al navegante, le comunica a la Reina la conclusión sacada, que no es otra, que el rechazo total al proyecto. 
El obispo de Palencia no se rinde, y le hace a la Reina la siguiente reflexión; ¿Y si las tierras que Colón piensa encontrar, estuviesen habitadas por seres a los que poder llevar la fe cristiana?. La Reina le pide calma y un poco de paciencia hasta que se pueda dar por terminada la conquista de Granada.

Colón deambula detrás de los Reyes, pero será Fray Diego de Deza quién consiga que el impaciente Colón acepte la espera. De ello son prueba fehaciente las cartas que en 1504 escribe Cristóbal Colón. En una dice: "el señor Obispo de Palencia siempre desque yo vine a Castilla, me ha favorecido y deseado bonra". En otra posterior dice: "el señor Obispo de Palencia fue causa de que sus altezas oviesen las Indias y que yo quedase en Castilla, que ya estaba yo camino para afuera" (previsiblemente a Francia, siguiente punto al que pensaba dirigirse).

Terminada la conquista de Granada, la Reina Isabel I de Castilla hablando en terminología actual, se convierte en la Presidenta del Consejo de Administración de la magna empresa del Descubrimiento. Ella respaldará y hará posible el que Colón con sus tres carabelas, cruce el Mar Tenebroso y encuentre fértiles tierras pobladas por aborígenes. La Reina para proteger los derechos de estos, crea bajo su auspicio las Leyes de Indias, modelo de código jurídico y marco legal para todas las tierras que se van a ir descubriendo.

Aquí hemos de hacer una reflexión. Estamos a finales de la Edad Media, y en la España de 1492 lo que se conquistaba con la intervención de los nobles, les era entregado bajo la denominación de Señoríos, con jurisprudencia civil y penal e incluso con ejército propio. Esto era válido no solo para España en toda la etapa de la Reconquista, sino también, en todo lo conquistado en la campaña de Nápoles.

A Isabel I de Castilla le pareció peligroso implantar los Señoríos en la lejana América, es decir, el poder absoluto de los nobles, permitiendo solamente el privilegio de las encomiendas.

Es de todos sabido que los encomenderos cometieron desmanes, pese a tener un marco legal que limitaba el tributo del indígena a un día semanal de trabajo no remunerado para el dueño de las tierras. El cómo aplicaron la ley estos encomenderos, es fácilmente previsible, cuando varios de ellos se atrevieron a solicitar del Papa Pablo III que declarase la irracionalidad del indio.

En 1994, la Reina Dña. Sofía en Madrigal de las Altas Torres, dijo que el apoyo generoso y la fe de la Reina Católica, habían hecho posible el que se estuviese celebrando el V Centenario. Pero son muchos más los castellanos que dejan su impronta en América, sobre todo durante los siglos XVI, XVII y XVIII. A estos, les podemos agrupar de la siguiente manera: obispos, gobernantes y comerciantes. 
En cuanto a los obispos sólo citaremos a los que llegaron a América. El licenciado Manso de Becerril de Campos (Palencia), fue quien por primera vez ostentó el cargo de obispo. Don Pedro Juárez de Deza, natural de Toro y canónigo del Obispado de Palencia, fue Obispo de Concepción de la Vega en América. Don Juan Rodríguez de Fonseca, natural de Toro y también Obispo de Palencia.

Aquí hemos de aclarar que la demarcación de Toro en aquel tiempo, era extensísima, ocupando gran parte de lo que en la actualidad es la confluencia de Zamora, Palencia y Valladolid, por lo tanto, en este territorio había muchos nobles. El hijo primogénito recibía toda la heredad y el segundón era en muchas ocasiones abad u obispo.

El más importante Obispado de España durante los siglos XV y XVI, fue el de Palencia. Valladolid no tuvo Obispado hasta 1598, aunque en esta ciudad estaba la Corte. Por lo anteriormente dicho, se da la circunstancia en muchas ocasiones, el ser natural de Toro y Obispo de Palencia.

El Obispo Rodríguez de Fonseca, enemigo de Colón y de sus privilegios, fue un personaje importante. Gobernador o Ministro de Indias desde 1492 hasta 1522, durante los treinta primeros años de la presencia de España en América, es decir, hasta que en 1522 se crea el Consejo de Indias en Valladolid.

Rodríguez de Fonseca no está en absoluto de acuerdo con las Capitulaciones en virtud de las cuales Colón es nombrado Almirante de las Indias y Duque de Veragua, él y su familia serán quienes gobiernen las tierras conquistadas, quedándose con todas las riquezas excepto un quinto de las mismas que entregarán a la Corona. El Obispo Fonseca consigue derogar casi todos estos privilegios en 1504.

Es también en este periodo de tiempo cuando tiene lugar un hecho histórico de capital importancia, El Tratado de Tordesillas, firmado en esta localidad castellana el siete de Junio de 1494 , cuyo V Centenario ha sido celebrado brillantemente por la Junta de Castilla y León el pasado año.

El Tratado de Tordesillas fue suscrito entre las Coronas de Portugal y Castilla. La cláusula de más enjundia disponía que se trazara una línea divisoria, de polo a polo, situada 370 leguas al oeste de la más occidental de las Islas de Cabo Verde.

El espacio comprendido al este del teórico meridiano, o, por decirlo con palabras de los negociadores "yendo por la dicha parte de levante, dentro de la dicha raya, a la parte de levante, o de norte o de sur" correspondería a Portugal, en tanto que lo situado al oeste, o sea, "yendo por la dicha parte de poniente, después de pasada la dicha raya, para el poniente, o el norte o el sur de ella", pertenecería a Castilla. 
En las mismas "Casas del Tratado" tordesillanas se alcanzó, en el histórico siete de Junio de 1494, otro acuerdo de positiva importancia. Las cláusulas del "Tratado Africano" delimitaban las posesiones de Portugal y Castilla en el Africa mediterránea y atlántica, cuestión que había suscitado, en el pasado, no pocos conflictos.

Las estipulaciones del Tratado de Tordesillas, sirvieron, como dice Rumeu de Armas, para poner fin, momentáneamente, a la "rivalidad entre Castilla y Portugal por la soberanía y el dominio del Océano Atlántico, de las islas diseminadas en su perímetro y de las tierras continentales aledañas". Al mismo tiempo, Portugal y Castilla, las dos Coronas de mayor solvencia en la navegación atlántica en las últimas décadas del siglo XV, señalaban, para uso exclusivo de unos y otros, dos grandes ámbitos de influencia y dominio.

A partir de 1494, Portugal y Castilla, avalados además por el poder arbitral del Pontífice de Roma, se repartieron el mundo. Y no extraña que tan ambicioso objetivo suscitara reticencias y protestas. A comienzos del siglo XVI, Francisco I de Francia, cuando conoció las resoluciones del Tratado de Tordesillas se preguntó "en virtud de qué cláusula del Testamento de Adán, Castilla y Portugal se proclaman herederos de los designios del mundo".

El Tratado de Tordesillas significó un avance en las relaciones diplomáticas entre los Estados. Castilla y Portugal, fueron capaces, a finales del siglo $\mathrm{XV}$, de solucionar sus diferencias sin necesidad de recurrir a métodos bélicos.

A continuación pasaremos a mencionar a castellanos que ocuparon importantes cargos en América, es decir, gobernantes. Durante los siglos XV y XVI, existieron en América dos Virreinatos: el de México y el de Perú. Desde mediados del siglo XVI hasta mediados del XVII, tres virreyes fueron palentinos, dos de Carrión de los Condes y uno de Frómista, los cuales dejan a los castellanos en muy buen lugar, pues su gobierno, según los que en su época vivieron, fue digno de las mayores alabanzas.

Luis de Velasco, nacido en Carrión de los Condes (Palencia) en 1511, murió en América en 1564. De la familia del Condestable de Castilla, casado con una mujer de alto rango, crea en 1549 para su hijo primogénito el Mayorazgo "Señorío de Salinas del Río Pisuerga". La extensión de sus posesiones era enorme, pues ocupaban todo el pueblo de Carrión, San Zoilo y varias villas más de los alrededores. Este hombre que en 1550 es nombrado virrey de México, llegó rico a América, y catorce años más tarde, en 1564, muere allí pobre. Las crónicas de la época que se escribieron en México, decían de él: "murió pobre en la hacienda, pero rico en fama y buena conciencia". 
Para Velasco, hombre íntegro, su gran preocupación fue defender a los aborígenes, provocando con ello el descontento de algunos españoles que querían enriquecerse rápidamente. Acepta e impone la igualdad de aquellos que pueblan esas tierras, es decir, la igualdad del indio. Crea en México la "Santa Hermandad", especie de fuerza de orden público, para evitar el bandidaje y el abuso que pudiesen padecer los aborígenes.

En el aspecto cultural su inquietud es mucha. A los hijos mayores de los caciques, los jefes de las tribus, que en su día dirigirán los cacicazgos, les educa en colegios religiosos, fundados para ese fin. Evidentemente, esto suponía una colonización a nivel cultural nada reprobable por otra parte.

También se preocupaba de que hubiese colegios para mestizos e hijos de españoles pobres, es decir, educación para todos. En el siglo XVI, fue todo un logro, ya que en España hemos tenido hasta bien entrado este siglo, pueblos sin escuelas.

En 1553, y bajo su mandato, se funda en México la Universidad, en ella estudiarán los hijos de españoles. Quién se encargó de poner en funcionamiento esta Universidad, a imagen y semejanza de la de Salamanca, fue Fray Juan de Zumárraga, prior del monasterio del Abrojo, todavía existente en el pueblo de Boecillo (Valladolid).

A este importante hombre le seguirá su hijo, también llamado Luis de Velasco y como su padre, nacido en Carrión de los Condes (Palencia). Regidor de México pasa en 1590 a ocupar el puesto de virrey, alll funda de acuerdo con su nombre, la ciudad de San Luis de la Paz. En 1596, pasa a ser virrey de Perú, volviendo como virrey de México en 1607. Finalmente en 1611, pasa a ser Presidente del Consejo de Indias. La importancia de estos dos palentinos, padre e hijo, es a todas luces indiscutible.

Otro palentino de Frómista, Fray García Guerra, es nombrado en 1607 Arzobispo de Nueva España, y en 1611, virrey de México, por lo que ocupa simultáneamente ambos cargos. En aquellas tierras americanas, de él se dijo: "como sacerdote fue virtuosisimo, y como gobernante, celoso del cumplimiento de la Ley". Murió de un golpe en la cabeza, de forma accidental, y de su entierro, dicen las crónicas de la época que fue multitudinario.

Aquí vamos a hacer una salvedad: ¿Por qué hablamos solo de palentinos?, por una sencilla razón, en esta provincia castellana tenemos más de doscientos personajes, quiere decir esto, que sería imposible poder hacer una relación del resto de las provincias, pues sería interminable, pero es evidente que lo que se refiere a Palencia, es extrapolable al resto de las provincias castellano leonesas. 
Para terminar con esta relación, pasamos al último apartado: los castellanos dedicados al comercio. Vamos a empezar a exponer algunas de las características del comercio con las Américas.

Desde Sevilla y dos veces al año, salía la flota de barcos que llevaban mercancías a América y que arribaban a Nueva España (México) o a Cartagena de Indias, para después dirigirse a Nombre de Dios (Panamá).

El comercio con la Argentina se hacía de la siguiente manera: las mercancías eran transportadas en carretas a través del istmo de Panamá hasta el Pacífico, donde se volvían a embarcar, navegando hacia el sur, para luego volver a transportarlas por tierra atravesando los Andes hasta la Argentina.

El comerciante del que a continuación hablaremos, se dedicaba al comercio de vinos. En documentos que aún se conservan, explicaba que los vinos debían ser de la mejor calidad, para que después de un viaje tan complicado, llegasen a la Argentina en buenas condiciones. El vino se vendía allá a un precio treinta veces superior al que se había pagado en Sevilla, donde antes de embarcar había que pagar el impuesto llamado "almojarizazgo".

Pedro Marcos "el indiano", (como él se apellidaba), aunque resulta curioso que este apelativo no aparezca hasta finales del siglo XIX en Galicia y Asturias, nace en Villalcázar de Sirga (Palencia), en el siglo XVI.

Este hombre perteneció al grupo de los "peruleros", es decir, comerciantes repartidos por el Perú que se reunían dos veces al año, entregaban el dinero de todos a uno de ellos y este iba algunas veces hasta Nombre de Dios (Panamá), para recoger las mercancías que llegaban de la flota de Sevilla, o bien iba a Sevilla y a otros puntos de España para hacer las compras para el grupo, y fue estando en el importante mercado de Medina del Campo, cuando pensó que estaba cerca de Villalcázar de Sirga, su pueblo natal, y se fue hasta allí, encontrándose tan a gusto que decidió quedarse. Al cabo del tiempo vuelve a Medina del Campo, y a un importante mercader llamado Espinosa le encarga comprar y llevar las mercanclas pedidas por los "peruleros".

Pedro Marcos, hombre soltero, invierte su dinero en tierras y "juros", acciones que emitían los Ayuntamientos. Crea una especie de fundación que mantiene un maestro y un cura, obligado este a decirle todos los "lunes del mundo" una misa rezada, y todos los "sábados del mundo" una misa cantada. Además, para que nadie en ese pueblo pasase hambre, crea un "pósito" o depósito de trigo, actualmente convertido en un renombrado mesón.

Otros castellanos importantes en la acción americana son: Diego Losada, fundador de Caracas; Juan Ponce de León, descubridor de la penín- 
sula de Florida y mas tarde colonizador de Puerto Rico; Diego Velázquez, fundador de Cuba; Juan de Garay, fundador de Buenos Aires.

Hablaremos a continuación del General San Martín (José Francisco de San Martín), nació en Yapeyú (Argentina) en 1778. Emancipador de la Nación Argentina, Chile y Perú. Hijo de Juan de San Martín, de Cervatos de la Cueza (Palencia) y de Gregoria Matorras, de Paredes de Nava (Palencia). En la casa natal del padre del General, encontramos la siguiente leyenda "de azores castellanos, nació el cóndor que sobrevoló los Andes".

De todo lo anteriormente se deduce que Castilla, sin paternalismos fuera de lugar, sí se ha sentido Madre. Y como tal ha entendido, que el General San Martín, hijo de castellanos y soldado durante casi veintidós anos de los ejércitos españoles en su lucha contra la invasión napoleónica, fuese el emancipador de estas tres naciones.

En la actualidad, en casi todas las provincias castellano leonesas existen Institutos Sanmartinianos donde se honra la figura de este gran hombre.

El 16 de Marzo de 1833, nace en Villada (Palencia), Carlos Casado del Alisal. Del hogar de los Casado saldrán dos hijos a correr mundo, para ganar fortuna y fama. De aquel modesto pueblo palentino, partirán un día dos muchachos, que tendrán después honroso renombre. Nacido un año antes que Carlos, su hermano José, figura entre los primeros pintores españoles de la segunda mitad del siglo XIX.

Carlos Casado del Alisal, hombre de gran formación, abandonó su profesión de navegante y armador después de sufrir dos graves naufragios y cruzó el Océano en busca de porvenir. Era otro emigrante dispuesto a labrarse una fortuna en suelo americano. Pero no era un emigrante más, su cultura y su preparación lo capacitaban para emprender la lucha en condiciones muy favorables, si se comparan con las que correspondían por entonces a la gran mayoría de quienes llegaban de Europa.

Casado del Alisal llegó al puerto de Buenos Aires en las postrimerías del año 1800. El País estaba en un momento crítico con la creación de un nuevo Régimen. Todo tenía que ser reorganizado a fuerza de trabajo y voluntad. Había un formidable potencial que estaba esperando cerebros y manos para comenzar a ser una enriquecedora realidad.

Hombre de empresa, no buscaba lo fácil, el tranquilo negocio en la urbe del Plata. Se marcha a Rosario, ciudad que pronto se convierte en la segunda mas importante de la República, y alli se dedica al comercio de importación y exportación con gran éxito. Con el progreso económico alcanza también prestigio moral. El 4 de Febrero de 1865 se casa con la argentina Ramona Sastre, y en aquel mismo año funda el primer establecimiento ban- 
cario de la Argentina. Emite billetes que llevan su firma y poseen pleno valor. El Banco Casado no tarda en relacionarse con organizaciones análogas del extranjero. Pero será en 1878 cuando comience la exportación a gran escala y metódicamente organizada de trigo argentino a Europa, utilizando sus propios barcos.

El Presidente de la Nación le concederá en 1879 la más alta distinción, la Medalla de Oro de la República Argentina con la siguiente inscripción: "Al distinguido y progresista ciudadano D. Carlos Casado".

La exportación exigía una nueva y potente organización, y el 4 de Noviembre de 1883 se inauguraría oficialmente el primer tramo de ferrocarril, que en lenguaje familiar todos llamarían "El Ferrocarril de Casado". Presidió esta inauguración el Presidente de la República General, Roca.

Murió en Rosario el 29 de Junio de 1899. La prensa registró con conmovidas expresiones su desaparición. "El Mensagero" dijo: ¡Qué hombre hemos perdidoj No sólo la guerra tiene genios, héroes y mártires; los tiene también la paz, y el señor Casado fue todo eso, y lo fue en alto grado.

Y para terminar en nuestros días nos encontramos con castellano-leoneses profundamente vinculados a América, como es el caso reciente de Obispo de Palencia, Nicolás Castellanos, el cual hace cuatro años abandonó su episcopado para instalarse en Santa Cruz de la Sierra (Bolivia), donde ha fundado el "Hospital Palencia", para atender a niños desnutridos. En su abnegada labor, es ayudado por un grupo de palentinos.

De la vinculación entre Castilla y América, se obtuvieron pronto resultados muy positivos, pues a finales del siglo XVI el Inca Garcilaso escribió bellísimos versos en lengua castellana.

Hoy en pleno siglo XX, tenemos grandes escritores en esta lengua nacidos en el Continente Americano.

De todo lo anteriormente dicho, y que es solo una pequenísima muestra de la vinculación de América con esta región española que es Castilla y León, se deduce que es posible estudiar la Historia, con un sentido objetivo claramente integrador. 
VINCULACIÓN HISTORICA ENTRE CASTILLA Y AMERICA A LO LARGO DE CINCO SIGLOS

\section{ORGANISMOS CONSULTADOS}

- ARCHIVO DE LA DIPUTACION PROVINCIAL DE PALENCIA

- BIBLIOTECA MUNICIPAL DE PALENCIA

- ARCHIVO DE INDIAS DE SEVILLA

- ARCHIVO HISTÓRICO DE SIMANCAS

- BIBLIOTECA DEL INSTITUTO SANMARTINIANO DE MADRID

- ARCHIVO CATEDRALICIO DE PALENCLA

- ARCHIVOS PARROQULALES DE LA PROVINCIA DE PALENCIA 